Check for updates

1 Institute of Population Health Sciences, Barts and the London School of Medicine and Dentistry, Queen Mary University, London, UK

2 Bradford Institute for Health Research, Bradford Royal Infirmary, Bradford

Correspondence to: T A Sheldon t.sheldon@qmul.ac.uk Cite this as: BMJ 2020;369:m2618 http://dx.doi.org/10.1136/bmj.m2618 Published: 30 June 2020

\title{
Twin epidemics of covid-19 and non-communicable disease
}

\section{Worse than the sum of their parts \\ Trevor A Sheldon, ${ }^{1}$ John Wright ${ }^{2}$}

The exclusive focus of political, regulatory, health service, and public health agencies on covid-19 has concealed another less visible epidemic.

Non-communicable diseases (NCDs) such as obesity, diabetes, heart disease, stroke, cancer, chronic respiratory diseases, and mental health disorders cause many times more premature deaths and greater suffering than covid-19, year after year.

Like children playing Sunday football, we have all been chasing after the covid-19 ball but have left the goal wide open. The response to coronavirus has constrained the physical and mental freedoms of people with NCDs and severely disrupted access to essential services. ${ }^{1}$ The management of the acute epidemic in isolation from the chronic epidemic is short sighted and will leave a legacy of great harm from the effect of lockdown and the serious disruption of health and care services for people with NCDs.

\section{Synergism}

These two epidemics are closely connected and act synergistically on morbidity and mortality: people with NCDs are more vulnerable to severe covid-19 and death ${ }^{2}$; covid-19 and NCDs share a common set of underlying risk factors, including deprivation, obesity, older age, and ethnicity.

Although communicable and non-communicable diseases seem very different, distinguished by transmissibility and chronicity, the dichotomy created by these categories is being challenged. ${ }^{3}$ An alternative concept of socially transmitted conditions has been proposed ${ }^{4}$ to reflect their shared social, environmental, and commercial ${ }^{56}$ determinants and to stress "the anthropogenic and socially contagious nature of the diseases." 4

The term socially transmitted conditions includes both communicable diseases such as covid-19 and NCDs such as diabetes. It signals clearly that these conditions are driven by upstream factors such as urban design, housing, poverty, the availability of tobacco, alcohol, and processed foods, and physical inactivity.

Public health policies to prevent disease and tackle the corporate and other social determinants of health have been frustratingly slow and chronically underfunded in the UK. ${ }^{7}$ Consequently, the UK lags behind many other industrialised countries in reducing premature mortality from NCDs, a poor starting point for a pandemic as challenging as covid-19.

Prevention strategies and research have focused on downstream interventions that rely on influencing individual behaviours, an approach that widens health inequalities. Interventions should instead target whole systems such as health, education, local government, and communities to tackle the underlying social economic and environmental causes of ill health. ${ }^{8}$

\section{Learning from covid-19}

Aspects of national responses to covid-19 can be learnt from and adapted to help tackle the equally devastating and much more durable epidemic of NCDs. Firstly, a strong cohesive national policy is urgently required, developed across all government departments and underpinned by legislation where needed, mirroring the emergency legislation introduced to control covid-19.

Policy, legislation, and regulation should target the key structural factors underlying epidemics of both covid-19 and NCDs, including income inequality, insecure employment, poor education, inadequate housing, and the societal risks driven by industries such as tobacco, alcohol, and processed foods. 69 Sweeping changes, including legislation, were made in a matter of weeks to protect the public from covid-19. We need the same urgency to stop the premature morbidity and mortality caused by NCDs.

Secondly, local systems must be strengthened. Coordinated action is needed by local decision makers with responsibility for housing, schools, local employment, transport, and the

environment-including strong community engagement. The covid-19 pandemic showed the power and agility of working through gold (strategic), silver (tactical), and bronze (operational) command structures to coordinate tailored local responses-from preparing hospitals through to supporting vulnerable citizens and developing community based recovery strategies. These well established emergency command structures should be deployed to control NCDs.

Thirdly, testing and tracking of covid-19 cases has a parallel in NCDs, where effective secondary prevention involves concerted action to identify and manage cases as early as possible. Rigorous, community based detection and follow-up of patients with hypertension, for example, reduce both morbidity and inequalities in stroke mortality. ${ }^{10}$ Some argue for parity between measures to reduce local variation in NCDs and measures to control infectious disease. ${ }^{11}$ Excess rates of some NCDs could be notifiable for example. Local and national public health agencies should develop a standardised incident response to clusters of premature NCDs, equivalent to that used for local outbreaks of infectious diseases. ${ }^{11}$

Action involving the whole health economy, and exploiting the wealth of surveillance data available 
from primary care databases, hospital statistics, and public health intelligence in real time, should be at the heart of our response to variations in NCD outcomes. ${ }^{12}$

Throughout the covid-19 epidemic, the government has pledged to "save lives." The lives of people with NCDs are equally important. Reducing mortality from NCDs requires both primary prevention to tackle the underlying causes and secondary prevention to ensure early detection and effective management. Our local and national response to covid-19 has shown what is possible with common purpose and collective endeavour. Let us put the same vigour and commitment into tackling the other pandemic.

Competing interests: We have read and understood BMJ policy on declaration of interests and have no relevant interests to declare.

Provenance and peer review: Commissioned; not externally peer reviewed.

1 WHO. Covid-19 significantly impacts health services for noncommunicable diseases. https://www.who.int/news-room/detail/01-06-2020-covid-19-significantly-impacts-health-servicesfor-noncommunicable-diseases

2 Kluge HHP, Wickramasinghe K, Rippin HL, etal. Prevention and control of non-communicable diseases in the COVID-19 response. Lancet 2020;395:1678-80 doi: 10.1016/S0140-6736(20)31067-9 pmid: 32401713

3 Adjaye-Gbewonyo K, Vaughan M. Reframing NCDs? An analysis of current debates. Glob Health Action 2019;12:. doi: 10.1080/16549716.2019.1641043 pmid: 31362599

4 Allen LN, Feigl AB. Reframing non-communicable diseases as socially transmitted conditions. Lancet Glob Health 2017;5:e644-6. doi: 10.1016/S2214-109X(17)30200-0 pmid: 28619214

5 Jahiel RI. Corporation-induced diseases, upstream epidemiologic surveillance, and urban health. J Urban Health 2008;85:517-31. doi: 10.1007/s11524-008-9283-x pmid: 18437580

6 Madureira Lima J, Galea S. Corporate practices and health: a framework and mechanisms. Global Health 2018;14:21. doi: 10.1186/s12992-018-0336-y. pmid: 29448968

7 House of Lords. The long-term sustainability of the NHS and adult social care. 2017. https://publications.parliament.uk/pa/ld201617//dselect/ldnhssus/151/15109.htm

8 Wright J, Hayward A, West J, etal. ActEarly: a city collaboratory approach to early promotion of good health and wellbeing. Wellcome Open Res 2019:4:156 doi: 10.12688/wellcomeopenres.15443.1. pmid: 31840089

9 Knai C, Petticrew M, Mays N, etal. Systems thinking as a framework for analyzing commercial determinants of health. Milbank Q2018;96:472-98. doi: 10.1111/1468-0009.12339 pmid: 30277610

10 Sheldon T. Vigorous implementation of effective care can reduce inequalities in health. J Health Serv Res Policy 2011;16:118-20. doi: 10.1258/jhsrp.2010.010155. pmid: 21447845

11 Knight J, Day M, Mair-Jenkins J, Bentley C, Anderson B, Khaw F-M. Responding to sustained poor outcomes in the management of non-communicable diseases (NCDs): an "incident control" approach is needed to improve and protect population health. BMC Public Health 2019;19:580. doi: 10.1186/s12889-019-6881-3 pmid: 31096950

12 Robson J, Boomla K, Hull SA. Progress in using the electronic health record to improve primary care. Br J Gen Pract 2020;70:e215-20. doi: 10.3399/bjgp20X708281 pmid: 32107248

This article is made freely available for use in accordance with BMJ's website terms and conditions for the duration of the covid-19 pandemic or until otherwise determined by BMJ. You may use, download and print the article for any lawful, non-commercial purpose (including text and data mining) provided that all copyright notices and trade marks are retained. 